\title{
Adaptive reprogramming during early seed germination requires temporarily enhanced fermentation - a critical role for alternative oxidase (AOX) regulation that concerns also microbiota effectiveness
}

Bharadwaj Revuru ${ }^{1,9}$, Carlos Noceda ${ }^{2,9}$, Mohanapriya Gunasekaran ${ }^{1,9}$, Sarma Rajeev Kumar ${ }^{1,9}$, Karine Leitão Lima Thiers ${ }^{3,9}$, José Hélio Costa ${ }^{3,9}$, Elisete Santos Macedo ${ }^{9}$, Aprajita Kumari ${ }^{4,9}$, Kapuganti Jagadis Gupta $^{4,9}$, Shivani Srivastava ${ }^{5,9}$, Alok Adholeya ${ }^{5,9}$, Manuela Oliveira ${ }^{6,9}$, Isabel Velada ${ }^{7,9}$, Debabrata Sircar ${ }^{8,9}$, Ramalingam Sathishkumar ${ }^{1,9 *}$, Birgit Arnholdt-Schmitt ${ }^{3,9 *}$,

1. Plant Genetic Engineering Laboratory, Department of Biotechnology, Bharathiar University, Coimbatore, India.

2. Cell and Molecular Biology of Plants (BIOCEMP)/Industrial Biotechnology and Bioproducts, Departamento de Ciencias de la Vida y de la Agricultura, Universidad de las Fuerzas Armadas-ESPE, Sangolquí, Ecuador

3. Functional Genomics and Bioinformatics Group, Department of Biochemistry and Molecular Biology, Federal University of Ceará, Fortaleza, Brazil

4. National Institute of Plant Genome Research, Aruna Asaf Ali Marg, 110067, New Delhi, India

5. Centre for Mycorrhizal Research, Sustainable Agriculture Division, The Energy and Resources, Institute (TERI), TERI Gram, Gual Pahari, Gurugram, India.

6. Department of Mathematics and CIMA - Center for Research on Mathematics and its Applications, Universidade de Évora, Évora, Portugal

7. MED-Mediterranean Institute for Agriculture, Environment and Development, Instituto de Investigação e Formação Avançada, Universidade de Évora, Évora, Portugal

8. Department of Biotechnology, Indian Institute of Technology Roorkee, Uttarakhand, India

9. Non-Institutional Competence Focus (NICFocus) 'Functional Cell Reprogramming and Organism Plasticity' (FunCROP), coordinated from Foros de Vale de Figueira, Alentejo, Portugal 


\title{
Corresponding authors:
}

\section{Birgit Arnholdt-Schmitt}

Non-Institutional Competence Focus (NICFocus) 'Functional Cell Reprogramming and Organism Plasticity' (FunCROP), coordinated from Foros de Vale de Figueira, Alentejo, Portugal; Email: 'biarnaflora@gmail.com'

\section{Ramalingam Sathishkumar}

Plant Genetic Engineering Laboratory, Department of Biotechnology, Bharathiar University, Coimbatore, Tamil Nadu, India - 641046

Email: rsathish@buc.edu.in

\begin{abstract}
: 250 words
\end{abstract}
Text: 3355 words

Figures: 02

Supplementary figures: 04

Supplementary tables: 02

\section{Supplementary files: 01}




\begin{abstract}
:
Plants respond to environmental cues via adaptive cell reprogramming that can affect whole plant and ecosystem functionality. Microbiota constitutes part of plant's inner and outer environment. This Umwelt underlies steady dynamics, due to complex local and global biotic and abiotic changes. Hence, adaptive plant holobiont responses are crucial for continuous metabolic adjustment at systems levels. Plants require oxygen-dependent respiration for energy-dependent adaptive morphology, such as, germination, root and shoot growth, formation of adventitious, clonal and reproductive organs, fruits and seeds. Fermentative paths can help in acclimation and, to our view the role of alternative oxidase (AOX) in coordinating complex metabolic and physiologic adjustments is underestimated.
\end{abstract}

Cellular level of sucrose is an important sensor of environmental stress. We explored the role of exogenous sucrose and its interplay with AOX during early seed germination. We found that sucrose-dependent initiation of fermentation during the first 12 hours after imbibition (HAI) was beneficial to germination. However, parallel enhanced AOX expression was essential to control negative effects by prolonged sucrose treatment. Early down-regulated AOX activity until 12 HAI improved germination efficiency in the absence of sucrose, but suppressed early germination in its presence. Our results also suggest that seeds-inoculated arbuscular mycorrhizal fungi can buffer sucrose stress during germination to restore normal respiration more efficiently.

Following this approach, we propose a simple method to identify organic seeds and low-cost on-farm perspectives for early selection on disease tolerance, predicting plant holobiont behavior and improving germination. Furthermore, our research strengthens the view that AOX can serve as powerful functional marker source for seed hologenomes.

Keywords: seed quality, ROS, Warburg effect, bacterial endophytes and mycorrhizal fungi, organic seeds, biotic stress, on-farm seed selection 


\section{Introduction:}

2 Understanding the role of microbiota in adaptive plant robustness is important for crop 3 improvement and for developing innovative tools that could allow more efficient plant 4 selection (Arnholdt-Schmitt et al., 2014, Nogales et al., 2015, Arnholdt-Schmitt et al., 5 2015, Arnholdt-Schmitt et al., 2018). Research on the relevance of endophytic and 6 associated microbiota and usage of microbiota inoculation are often hampered by low 7 reproducibility, which is due to a lack of better understanding the fundamental principles 8 of functional plant-microbiota interaction (Arnholdt-Schmitt, 2008, Vicente and Arnholdt9 Schmitt, 2008, Mercy et al., 2015, Campos et al., 2015, Mercy et al., 2017, Bedini et al., 2018). Albornoz et al. (2020) emphasizes the need for studying mycorrhizal benefits on a case-by-case basis that should consider more holistic and context-dependent views on mycorrhiza functioning at plant family- and biome-wide levels. Also, it is widely confirmed that endophyte effects are genotype-specific (Abdelrazek et al., 2020a,b). Further, Durán et al. (2018) identified bacterial endophytes as drivers for soil suppressive take-all disease. Nevertheless, they highlighted that they did not find relevant correlation between disease suppression and reduced pathogen biomass. In our opinion, these are key observations. They encourage us to continue working on the hypothesis that individual plant host's competence for resilience plays the most critical role for beneficial or nonbeneficial plant - microbiota interaction, which can be superior to plant families and biome origins.

However, there is lack of knowledge on traits that aid in (a) early prediction of the strength of plants and (b) demonstration of its relevance for plant-microbiota interactions and (c) transformation of such knowledge into user- and environment-friendly applications for sustainable agriculture. We earnestly aim with our perspective to understand these phenomena and to contribute to the knowledge base towards closing these three gaps.

The capacity for efficient reprogramming as a trait per se is recognized as marker for adaptive plant robustness (Cardoso and Arnholdt-Schmitt, 2013). Seed germination can serve as an experimental in vitro tool to study environmental stress-induced reprogramming and to identify early functional markers and tools for predicting plant performance under field conditions (Mohanapriya et al., 2019). Dry seeds are known to respond to water imbibition and subsequent penetration of oxygen. Thus, radicle 
emergence can be seen as an indicator of environmental stress recovery from the dry-towater imbibed conditions and low-to-high oxygen status.

Efficient seed germination under field conditions is especially required in organic agriculture, where application of chemical herbicides for suppressing weed competition and pesticides shall be avoided in support of healthy food and feed production and to improve sustainability of bio-based socio-economic systems. At the same time, organic agriculture impacts seeds quality and the amount of microbiota in seeds (Naomi CopeSelby et al., 2017, Wassermann et al., 2019). Recently, the use of the so-called 'organic seeds' versus conventionally produced seeds is raised as an ethical issue (www.liveseed.eu; effective European regulation from 1.1.2021: EC No 2018/848). However, the better quality of organic seeds in terms of their contribution to agriculture sustainability, nutritional quality and yield performance is under intensive debate (e.g. Voss-Fels et al., 2019, Bhaskar et al., 2019) and requires scientific clarification (Simon et al., 2017, Abdelrazek et al., 2020a,b). Appropriate methods and tools are the need of the time in order to discriminate organic versus conventional seeds by traits that should at the same time allow predicting the assumed superior quality of organic seeds.

\section{Background:}

Cellular reprogramming is an energy intensive phenomenon. Reactive oxygen species (ROS) are known to interact with redox-sensitive protein cysteine thiol groups relevant for energy metabolism and metabolic channeling linked to cell differentiation and cell cycle regulation (Bigarella et al. 2014, Dumont and Rivoal, 2019; Qi et al., 2020; Gupta et al. 2020a, Gupta et al., 2020b, Pengpeng et al., 2020). Sugars and sugar phosphates interact with hormone-mediated signaling networks to modulate energy metabolism. Auxinstimulated sugar metabolism was frequently reported (e.g. Zhao et al., 2021). But only few examples revealed that sucrose can induce new cell programs (Grieb et al., 1994, see in Zavattieri et al., 2010) and also, vice versa, can change auxin metabolism (Lin et al., 2016, Meitzel et al., 2020). In maize, sucrose stimulated more cell cycle markers during germination than glucose (Lara-Núñez et al., 2017). Down-stream of sugars, two important antagonistic protein kinases are involved in energy sensing and physiological adaptation (reviews in Bayey-Serres et al., 2018, Schmidt et al., 2018, Sakr et al., 2018). While sucrose non-fermenting-1-related protein kinase1 (SNRK1) is activated when energy is depleted 
67 (Schmidt et al., 2018, Wurzinger et al., 2018; Wang et al., 2020), TOR (target of 93

rapamycin) is induced under conditions of energy excess and stimulates cell cycle progression and cell proliferation (Sangüesa et al., 2019). Sucrose can have various functions: besides its nutritional role it acts as signaling component (Baena-Gonzalez et al., 2017, Sakr et al., 2018), as osmotic stressor that can disrupt communication within and between cells (Moon et al., 2015) and was shown to trigger aerobic alcohol fermentation in support of respiration and biosynthesis of higher molecular weight compounds, such as lipids (Mellema et al., 2002). Alcohol fermentation was found to play critical role in controlling tissue level pyruvate in plants and, thereby, adapt respiration rates to the prevailing cellular energy status (Zabalza et al., 2009). Fan et al. (2020) identified hormone and alcohol degradation pathways as the most activated during early stages of somatic embryogenesis (SE), which is a prominent example of de novo programming. Ethanol has been shown to reduce ROS levels and led to high induction of alternative oxidase (AOX) and glutathione-S-transferase transcripts (Nguyen et al., 2017). Transcriptome analyses at 2,4-D - induced reprogramming indicated that the extent of aerobic fermentation is connected to cell proliferation and was regulated by interacting levels of sucrose and AOX (Costa et al., 2021; preprint). Transient up-regulation of genes related to alcoholic and lactic fermentation was shown to be associated with glycolysis and modified complex stress signaling patterns with enhanced superoxide dismutase and decreased transcript levels of nitric oxide - producing nitrate reductase. Further, our data signaled activation of cell death-regulating system and arrested cell cycles at reduced alpha-tubulin transcription at the earliest step in reprogramming. Considering generality of these observations, we proposed a reference transcriptome profile to identify virus traits that link to harmful reprogramming (Arnholdt-Schmitt et al., 2021 In Press). This approach helped identifying an early trait for combating SARS-CoV-2 that covers ROS/RNS balancing, aerobic fermentation regulation and cell cycle control (Costa et al., 2021; preprint).

In seeds, fermentation and alternative respiration are dominating (references in ArnholdtSchmitt et al., 2018, Mohanapriya et al., 2019). During seed germination, structural and functional acclimation of aerobic respiration is central and determines temperaturedependent efficiency of germination (Bello and Bradford, 2016, Gaël Paszkiewicz et al., 2017). Nevertheless, markers for respiration and oxygen consumption were not superior to 99 simple germination tests for predicting seed vigor from single seeds (Powell et al., 2017).

00 However, it was suggested that alternative respiration plays the most critical role during 
101

germination (Arnholdt-Schmitt et al., 2018 and references herein, Mohanapriya et al., 2019). This role requires managing ROS/RNS increase and channeling energy and substance flow from fermentation when carbohydrate storages are released and enzymes get into motion (Saleh and Kalodimos, 2017), but the respiration chain is still structurally restricted and overloaded at massively incoming oxygen. AOX is mainly regulated by pyruvate (Millar et al, 1996, Hoefnagel et al., 1997, Albury et al., 2009, Hakkaart et al., 2006, Carré et al., 2011, Selinski et al., 2018) and, strikingly, Ito et al. (2020) showed in Arum that energy-related metabolic regulation can be determined by temperaturedependent switching between AOX polymorphisms in the binding site for AOX-pyruvate. In this scenario, it might be of interest that AOX was essential in ethylene-induced drought tolerance and mediating autophagy generation via balancing ROS levels (Zhu et al., 2018). Thermo-inhibition of carrot seed germination could be circumvented by seed priming, which was found to be linked to increased ethylene production at higher temperatures (Nascimento et al., 2013). Ethylene biosynthesis was found to be induced by $\mathrm{H}_{2} \mathrm{O}_{2}$ and acted positively on germination independently from auxin-coordinated hormonal crosstalk linked to ABA suppression and gibberellin activation (Wojtyla et al., 2016). During plant ethylene biosynthesis cyanide is generated as by-product of the pathway and suspected to help shifting cyt respiration to alternative respiration (Siegieñ and Renata Bogatek, 2006, Machingura et al., 2016). Eckert et al. (2014) stressed that microbiota have developed ethylene-producing pathways to profit during invasion and to evade from defense responses of the host plants. Mercy et al. (2017) observed that KCN treatment of mycorrhizal seedlings promoted local arbuscular formation.

Recently, we identified AOX as stress level - sensing coordinator for auxin-inducible metabolic reprogramming by comparing induction of SE and seed germination (Mohanapriya et al., 2019; see also Arnholdt-Schmitt et al., 2018). Association of AOX to target cell reprogramming was also observed in other systems such as adventitious root induction in olive (Macedo et al., 2009, Porfirio et al., 2016) and elicitor-induced hairy roots (Sircar et al., 2012). Furthermore, our group had contributed to novel functional marker strategies by highlighting $\mathrm{AOX}$ as a marker across taxonomic boarders that considered 'shared' $A O X$ genes in plant holobionts (Arnholdt-Schmitt 2005a and b, Arnholdt-Schmitt et al., 2006, Arnholdt-Schmitt, 2008, Campos et al., 2015, Mercy et al., 2017, Bedini et al., 2018). Based on the role of AOX in carbohydrate metabolism (Vanlerberghe et al., 1994), our approach stimulated reflecting on the role of fermentation 
and sugars for plant -mycorrhiza interaction (Mercy et al., 2017, Bedini et al., 2018) and had led to a privately explored patent (Mercy and Mercy, 2014). However, the early phase of reprogramming was not sufficiently considered in that research (Mercy et al., 2017) to drive our core functional marker approach (Arnholdt-Schmitt, 2008, Mercy et al., 2015). Recently, Mohanapriya et al. (2019) observed that AMF inoculation in imbibed seeds interacted with the AOX-inhibitor SHAM and palliated negative SHAM effects on early germination. Also, AMF effects in seeds seemed to be modified by non-culturable microbiota. Integrated in silico studies on experimental data revealed that endophytes interact with AOX expression in a species-, stress-, and developmental-dependent manner. Enterobacter species could reduce salt-induced expression of AOX1a and kept its mRNA level low when applied together with salt. Costa et al. (2021; preprint) highlighted that microbiota - plant genotype interaction and its impact on early carrot seed germination can be modified by SHAM.

In our earlier work (Mohanapriya et al. 2019), we demonstrated successful prediction by oxycaloric equivalents from germinating seeds at 10 HAI. The present perspective questions the metabolic nature of AOX coordination and provides deeper phenotyping during germination of endophyte-free and microbiota-inoculated seeds focused at early times around 12 HAI. Figure 1 demonstrates the step-by-step rationale of fundamental insights and deduced practical strategies.

In summary, we found that (a) during Arabidopsis thaliana seed germination $A D H$ transcript levels increased $12 \mathrm{~h}$ after seed stratification in water followed by a decline and that increase in $\mathrm{ADH}$ transcript levels was in general accompanied by increased AOX1a transcript accumulation (Figure 1.B.2) (b) in agreement with (a), germinating carrot seeds displayed a higher level of biochemically determined ADH at $12 \mathrm{HAI}$ than at $24 \mathrm{HAI}$. In the presence of $3 \%$ sucrose, this level was enhanced (Figures 1.A.3 and 1.B.3) (c) short pulses of sucrose of $2 \mathrm{~h}$ at water imbibition enhanced early germination in seeds of two different species, viz., carrot and wheat (Figures 1.A.2, S2, 1.E.3). In carrot, we showed that the effectiveness of such early sugar pulse was dependent on sucrose concentration. A short pulse could be substituted by a longer pulse at a lower concentration of sucrose (Figure 1.A.2) (d) to the contrary, SHAM treatment until 6 HAI and 12 HAI suppressed germination in the presence of $3 \%$ sucrose. However, it favored early germination in the absence of sucrose (Figure 1.C.1). 
170 (e) Three carrot native bacterial endophytes were used for carrot seed inoculation on two 171 cultivars and showed a tendency to improve germination (Figure 1.D.1). However, a 172 positive effect was dependent on cultivar-endophyte interaction. SHAM treatment reduced 173 early germination percentage of endophyte-treated seeds against the respective endophyte174 treated controls. This was observed in all cases though to a different degree (Figure 1.D.2 and table S2) (f) sucrose had differential impacts on endophyte-mediated effects on germination and was dependent on cultivar and endophytes. However, in no case endophytes improved germination of sucrose-treated seeds to higher levels than the endophyte-treated controls without sucrose (Figure 1.D.2 and table S2) (g) In a good germinating carrot cultivar, the two selected Rhizophagus strains acted both negatively on

180 early germination, while in a later germinating carrot cultivar, both Rhizophagus strains acted positively (Figure 1.D.1 and table S2). Sucrose could improve Rhizophagus effects on early germination to higher levels than the AMF-treated controls in both the cultivars. However, this was dependent on cultivar-strain interaction. In the presence of sucrose, strain M1 improved germination of both cultivars compared to M1-treated control seeds (Figure 1.D.2). (h) at lower concentrations of SHAM (5 mM), early germination could be improved to higher levels as compared to the AMF-treated controls (Figure 1.D.2), but this was observed only in the better germinating cultivar, which had not shown positive AMF effects against non AMF-treated controls (Figure 1.D.1 and table S2)

In Figure 2, we present a simplified scheme that summarizes our conclusions based on wet-lab experiments, state-of-the-art knowledge and our hypothetical inferences related to the dynamic metabolic interplay between sucrose, aerobic fermentation, cyt respiration, AOX regulation/alternative respiration, and microbiota on cell reprogram functioning. In this scheme, we separate AOX as a macromolecule (gene/protein) from the functional pathway, the alternative respiration, to highlight the outstanding position of AOX as the key and only enzyme of a pathway that, if present in an organism, was recognized to provide a central metabolism-coordinating function for efficient survival (Mohanapriya et al., 2019, Arnholdt-Schmitt et al., 2021 In Press, Costa et al., 2021; preprint). We consider that under development- and/or environment-induced conditions of rapid sucrose increase, the Cyt pathway is stimulated via enhanced glycolysis, pyruvate production and increased TCA cycling in a way that the respiration chain can get overloaded by electrons followed by enhanced ROS/RNS levels and, on the other hand, restricted due to rapidly consumed 
oxygen and/or yet low numbers of functional mitochondria in relation to available oxygen during germination. In turn, aerobic alcoholic and lactic fermentation are stimulated (see points a), b) and c), and Costa et al., 2021; preprint). At the same time, AOX is activated (see point d) and in Mohanapriya et al., 2019, Costa et al., 2021; preprint) mainly through AOX gene sequence-dependent pyruvate regulation and ROS/RNS.

Depending on stress level and the amount of sucrose and duration of a situation of high sugar-level, anaerobic glycolysis can reach high turnover during cell reprogramming and a level of high ATP production even corresponding to the Warburg effect. This latter hypothesis is supported by a parallel research on auxin-induced callus growth (Costa et al., 2021; preprint) where we observed a rapid and high increase in $A D H 1$ transcripts of $1777 \%$ and a parallel increase in $L D H$ transcripts of $346 \%$. Warburg effects are increasingly recognized also in human systems (Melkonian and Schury, (2020), Kutschera et al., 2020) as being part of normal physiology. However, in plants they are studied still more in relation to photosynthesis (Kutschera et al., 2020) and anaerobic conditions are best explored in relation to anaerobic conditions under flooding and was related to anaerobic tolerance in rice (Narsai et al., 2017). It was shown that, AOX plays beneficial role under low oxygen and especially during re-oxygenation (Jayawardhane et al., 2020).

Under increased sucrose, fermentation can escape feedback down-regulation by the help of enhanced alternative respiration, since AOX-transferred electrons enable continuation of TCA cycling for metabolic re-organization though with a relatively less energy efficiency. Thus, fermentation and AOX are complementing each other in order to maintain metabolic and energetic homeostasis thereby avoiding inefficient situations when the respiration chain is overloaded in relation to oxygen availability. As soon as oxidative stress gets sufficiently diminished at equilibrated oxygen availability in the cyt pathway, AOX will be down-regulated and normal respiration will reach priority again for driving growth and development. Fermentation and AOX will again be regulated in adaptation to sucrose- and cyt respiration-transmitted conditions embedded in adaptive hormonal crosstalk and overall complex cellular and apoplastic network signaling. Thus, rapid downregulation indicates efficient adaptation of cyt respiration, a dynamic trait appropriate to mark seed vigor (Mohanapriya et al., 2019). 
236 Sucrose can improve early germination of Rhizophagus-treated seeds (see point g) while

237

238

239

240

241

242

243

244

245

246

247

248

249

250

251

252

253

254

255

256

257

258

259

260

261

262

263

264

265

266

267

268

non-AMF-treated seeds respond upon sucrose typically with a delay in germination (see

Figure 1.A.1). This suggests that AMF can alleviate or buffer negative effects of sucrose on germination to relevant degrees by providing an additional sink. This was not indicated for the three tested endophytes (f). Also, early germination of endophyte-treated seeds was reduced at 48 HAI by continuously present SHAM when compared to seed germination of the respective endophyte-treated controls (e). To the contrary, when seeds from the good germinating cultivar were inoculated with Rhizophagus, SHAM treatment $(5 \mathrm{mM})$ could improve early germination to higher levels than observed in AMF-treated controls. This observation is in agreement with the palliating effects observed by Scutellospora calospora on negative SHAM effects on carrot germination by using the same cultivar (Mohanapriya et al., 2019). In an overall assessment, it is inferred that AMF treatment might improve early germination by alleviating stress by rapid sucrose excess through two mechanisms: providing an additional sink for sucrose and supplying an enhanced capacity and/or engagement of alternative respiration. Rhizophagus spores were shown to be a rich source for polymorphic AOX gene sequences (Campos et al., 2015). We believe that there could be operation of two separate mechanisms, since we observed differential effects on early germination of M1-treated seeds upon SHAM-treatment in the two selected cultivars (Figure 1.D). However, M1-treated seeds of both cultivars showed improvement in early germination when sucrose was provided (Figure 1.D). We tend to interpret that the isolated native carrot endophytes were already well integrated into the internal host cell habitat. Thus, their re-inoculation tended to influence early germination positively, but could not provide a striking new advantage or disadvantage when sucrose was enhanced or SHAMtreatment reduced the level of alternative respiration. However, we reported that endophytes modulate $A O X$ transcripts in a species-, stress-, and development-dependent manner and that endophytes could have modified the effect of AMF inoculation on seed germination efficiency (Mohanapriya et al. 2019).

\section{Outlook:}

Our observations offer new perspectives for low-cost prediction of plant holobiont behavior from seeds and for providing simple and rapid on-farm support towards sustainable agriculture. We propose three tools for validation: 
269 A) Seed selection by help of short germination tests under SHAM discrimination. This tool 270 provides modalities to identify seeds with higher seed vigor, general adaptive plant

271 robustness and superior internal seed quality related to the content of secondary metabolites

272 (Figures 1.E.1, 1.E.2, S3 and S4)

273 B) Discrimination of organic versus conventionally produced seeds with the help of short

274 duration germination tests in water solutions with 5\% commercial sugar (Figure 1.E.1)

275 C) Germination improvement by 2 h pulses of commercial sugar (Figures 1.A.1, S1, 1.E.3)

277 Furthermore, we encourage developing novel tests for AMF functionality in germinating

278 seeds in the presence of sucrose. This approach targets compatibility between selected 279 plants and AMF strains to support plant holobiont plasticity.

280

281 Our results suggest that polymorphic AOX gene sequences of symbiotic partners can 282 impact plant-AMF compatibility. Therefore, we want to accomplish wider screening of 283 major $A O X$ polymorphisms in species-specific target cells for evaluating plant performance 284 (Abe et al., 2002, Arnholdt-Schmitt et al., 2006, Arnholdt-Schmitt, 2015, Nogales et al., 285 2016) and in AMF sources (Arnholdt-Schmitt, 2008; Vicente and Arnholdt-Schmitt, 2008, 286 Campos et al., 2015). Such strategy needs to also include near neighboring polymorphisms 287 in conserved functional sites that can discriminate differentially regulated $A O X 1$ and $A O X 2$ 288 (Costa et al., 2009). This approach would include screening of compatible AOX 289 polymorphisms from both partners in the proposed functional tests to identify best plant290 AMF combinations.

292 We hypothesize that the observed integration of bacterial endophytes into host plants with similar sensitivity against SHAM effects might point to synchronized AOX regulation in plant holobionts. Into this derivation would fit that we observed the same tendency of inhibiting sucrose effects on endophyte-free and superficially sterilized seeds (Figure 1.A.1), which we noticed also for SE induction (unpublished). Vicente et al. (2015) highlighted a 'provocative' lack of interest in bacterial AOX. They anticipated that bacteria-harboring AOX could facilitate adaptation to extreme conditions, which could also be of interest when thinking on plant endophytes and AMF-associated bacteria (Pandit et al., manuscript under preparation). 
302 This present perspective is complementing Mohanapriya et al. (2019) and Costa et al.

303 (2021; preprint). Joining the central figures of these publications is thought as one teaching 304 tool that can help explaining a straightforward way from fundamental interdisciplinary 305 research to application that might support sustainable socio-economies in view of the 306 diversity of emergent environmental changes.

\section{Author Contributions:}

309 BR performed lab analyses on carrot germination, endophyte isolation and inoculation 310 trials related to Figures 1.A.1-3, 1.B.3, 4 and 5, 1.C.1 and 2, and 1.D. JHC coordinated 311 transcriptome analyses supported by KTL. JHC, RS and CN discussed initially the 312 approach of this manuscript with BAS. GM carried out work on Figure S1 and Table S1. 313 SS was responsible for AMF inoculation trials under the head of AA, ESM performed pea 314 studies for Figure E.2 under responsibility of BAS. Under supervision of KJG, ESM 315 together with AK performed germination analyses of transgenic Arabidopsis, and AK 316 carried out the ADH analyses on chickpea. BAS performed on farm analyses (Figures 1.E.1 317 and 1.E.3). CN was responsible for statistics and was in part supported by MO. BR and IV 318 helped BAS in literature search. DS contributed with Figure S3. BAS initiated the scientific approach, coordinated overall research and discussion and wrote the manuscript. All coauthors commented research and manuscript during its development and agreed to manuscript submission. BR organized manuscript submission.

\section{Acknowledgments:}

RS, GM and BAS acknowledge support for academic cooperation and researchers mobility by the India-Portugal Bilateral Cooperation Program (2013-2015), funded by "Fundação para a Ciência e Tecnologia" (FCT), Portugal, and the Department of Science and Technology (DST), India. GM is grateful to UGC, India, for doctoral grant from BSR fellowship. KJG, MO and BAS acknowledge support by the India-Portugal Bilateral Cooperation Program 'DST/INT/Portugal/P-03/2017'. MO Research is partially supported by National Funds through FCT, Fundação para a Ciência e a Tecnologia, projects UIDB/04674/2020 (CIMA). BAS wants to thank RS for enabling intensive external online supervision of BSR on the presented research and excellent collaboration and communication of BSR. BR and SS acknowledge the infrastructure and stay support 
and innovation (DTD-RNA) for AMF related work at The Energy and Resources Institute, TERI, India. JHC is grateful to $\mathrm{CNPq}$ for the Researcher fellowship (CNPq grant 309795/2017-6). KTL is grateful to CNPq for the Doctoral fellowship. BAS is grateful to SRK for his support in facilitating coordination of the Indian FunCROP team. CN acknowledges the international scientific network BIOALI-CYTED, which contributed to establish FunCROP contacts. BAS wants to acknowledge especially the extraordinary engagement of $\mathrm{CN}$ for online collaboration with BSR on data evaluation and presentation and overall manuscript discussion. BAS appreciates collaboration of LIVESEED partners with seed material and information on this material and thanks for supporting ESM (European Horizon2020 project LIVESEED GRANT NO. 727230).

\section{References:}

Abdelrazek, S., Choudhari, S., Thimmapuram, J., Simon, P., Colley, M., Mengiste, T., Hoagland, L. (2020a). Changes in the core endophytic mycobiome of carrot taproots in response to crop management and genotype. Sci Rep 10(1):13685. doi: 10.1038/s41598-020-70683-x.

Abdelrazek, S., Simon, P., Colley, M., Mengiste, T., Hoagland, L. (2020b) Crop management system and carrot genotype affect endophyte composition and Alternaria dauci suppression. PLoS One 15(6):e0233783. doi: 10.1371/journal.pone.0233783.

Abe, F., Saito, K., Miura, K., Toriyama, K. (2002). A single nucleotide polymorphism in the alternative oxidase gene among rice varieties differing in low temperature tolerance. FEBS Lett. 527(1-3), 181-5. doi: 10.1016/s0014-5793(02)03218-0.

Albornoz, F.E., Orchard, S., Standish, R.J., Dickie, I.A., Bending, G.D., Hilton, S., et al. (2020). Evidence for Niche Differentiation in the Environmental Responses of Cooccurring Mucoromycotinian Fine Root Endophytes and Glomeromycotinian Arbuscular Mycorrhizal Fungi. Microb Ecol. doi: 10.1007/s00248-020-01628-0.

Albury, M.S., Elliott, C, Moore A.L. (2009). Towards a structural elucidation of the alternative oxidase in plants. Physiol Plant. 137(4), 316-27. doi: 10.1111/j.13993054.2009.01270.x.

Arnholdt-Schmitt. (2005a). Efficient cell reprogramming as a target for functional-marker strategies? Towards new perspectives in applied plant-nutrition research. $Z$. Pflanzenernähr. Bodenk. 168, 617-624.

Arnholdt-Schmitt B. (2005b). Functional markers and a 'systemic strategy': convergency between plant breeding, plant nutrition and molecular biology. Plant Physiol Biochem. 43(9), 817-20. doi: 10.1016/j.plaphy.2005.08.011.

Arnholdt-Schmitt, B. (2008). A novel gene-candidate approach of socio-economic interest? Breeding on efficient plant genotype - mycorrhiza interaction. Proceedings of COST 
bioRxiv preprint doi: https://doi.org/10.1101/2021.06.08.447570; this version posted June 10, 2021. The copyright holder for this preprint (which was not certified by peer review) is the author/funder. All rights reserved. No reuse allowed without permission.

870 meeting "From production to application of arbuscular mycorrhizal fungi in agricultural systems: a multidisciplinary approach", Denmark, May 27-30, p.47-50.

Arnholdt-Schmitt, B., Costa, J.H., de Melo, D.F. (2006). AOX--a functional marker for efficient cell reprogramming under stress? Trends Plant Sci. 11(6), 281-7. doi: 10.1016/j.tplants.2006.05.001.

Arnholdt-Schmitt, B. (2015). From AOX diversity to functional marker development. In Alternative respiratory pathways in higher plants eds. KJ. Gupta, LAJ MuR, B NeelwarnE (Oxford: John Wiley \& Sons), 233-243

Arnholdt-Schmitt, B., Mohanapriya, G., Sathishkumar, R., Macedo, E. S., Costa, J. H. (2018). Predicting biomass production from plant robustness and germination efficiency by calorespirometry in Biofuels: Greenhouse Gas Mitigation and Global Warming. Next Generation Biofuels and Role of Biotechnology. eds. A. Kumar, S Ogita, Y Yau. (Springer Nature), 81-94

Arnholdt-Schmitt, B., Valadas V, Döring M. (2016). Functional marker development is challenged by the ubiquity of endophytes-a practical perspective. Brief Funct Genomics 15, 16-21. doi: 10.1093/bfgp/elu049.

Arnholdt-Schmitt, B., Valadas, V., Doering, M. (2014). Functional marker development is challenged by the ubiquity of endophytes - a practical perspective. Briefings on Functional Genomics 10.1093/bfgp/elu049.

Arnholdt-Schmitt, B., Mohanapriya, G., Bharadwaj, Revuru., Noceda, C., Macedo, E.S., Sathishkumar R, et al. (2021). From Plant Survival Under Severe Stress to Anti-Viral Human Defense- A Perspective That Calls for Common Efforts. Front. Immunol. 12:673723 (In Press). doi: 10.3389/fimmu.2021.673723

Baena-González, E., Hanson, J. (2017). Shaping plant development through the SnRK1-TOR metabolic regulators. Curr Opin Plant Biol. 35, 152-157. doi: 10.1016/j.pbi.2016.12.004.

Bailey-Serres, J., Pierik, R., Ruban, A., Wingler, A. (2018). The Dynamic Plant: Capture, Transformation, and Management of Energy. Plant Physiol. 176(2), 961-966. doi: 10.1104/pp.18.00041.

Bedini, A., Mercy, L., Schneider, C., Franken, P., Lucic-Mercy, E. (2018). Unraveling the initial plant hormone signaling, metabolic mechanisms and plant defense triggering the endomycorrhizal symbiosis behavior. Front. Plant Sci. 9:1800.

Bello, P., \& Bradford, K. (2016). Single-seed oxygen consumption measurements and population-based threshold models link respiration and germination rates under diverse conditions. Seed Science Research. 26(3), 199-221. doi:10.1017/S0960258516000179.

Bhaskar A.V.V., Baresel, J.P., Weedon, O., Finckh, M.R. (2019). Effects of ten years organic and conventional farming on early seedling traits of evolving winter wheat composite cross populations. Sci Rep. 9(1):9053. doi: 10.1038/s41598-019-45300-1. 
bioRxiv preprint doi: https://doi.org/10.1101/2021.06.08.447570; this version posted June 10, 2021. The copyright holder for this preprint (which was not certified by peer review) is the author/funder. All rights reserved. No reuse allowed without permission.

Bigarella, C.L., Liang, R., Ghaffari, S. (2014). Stem cells and the impact of ROS signaling. Development. 141(22), 4206-18. doi: 10.1242/dev.107086.

Boratyn, G.M., Thierry-Mieg, J., Thierry-Mieg, D., Busby, B., Madden, T.L. (2019). MagicBLAST, an accurate RNA-seq aligner for long and short reads. BMC Bioinformatics 20(1):405. doi: 10.1186/s12859-019-2996-x.

Campos, C., Cardoso, H., Nogales, A., Svensson, J., Lopez-Ráez, J.A., Pozo, M.J., et al. (2015). Intra and Inter-Spore Variability in Rhizophagus irregularis AOX Gene. PLoS One 10(11):e0142339. doi: 10.1371/journal.pone.0142339.

Cardoso, H.G., Arnholdt-Schmitt, B. (2013). Functional Marker Development Across Species in Selected Traits In Diagnostics in Plant Breeding. eds. T Lübberstedt, RK Varshney (Springer Netherlands), 467-515.

Carré, J.E., Affourtit, C, Moore, A.L. (2011). Interaction of purified alternative oxidase from thermogenic Arum maculatum with pyruvate. FEBS Lett. 585(2), 397-401. doi: 10.1016/j.febslet.2010.12.026.

Cope-Selby, N., Cookson, A., Squance, M., Donnison, I., Flavell, R. and Farrar, K. (2017). Endophytic bacteria in Miscanthus seed: implications for germination, vertical inheritance of endophytes, plant evolution and breeding. GCB Bioenergy. 9, 57-77.

Costa J.H., Cardoso, H.G., Campos, M.D., Zavattieri, A., Frederico, A.M., de Melo, D.F., et al. (2009). Daucus carota L. - an old model for cell reprogramming gains new importancethrough a novel expansion pattern of alternative oxidase (AOX) genes. Plant Physiol.Biochem. 47 (8):753-759. doi: 10.1016/j.plaphy.2014.11.013. Costa, J. H.,Cardoso, H. G., Campos, M. D., Zavattieri, A., Frederico, A. M., de Melo, D. F., et al.Corrigendum to "Daucus carota L. - an old model for cell reprogramming gains newimportance through a novel expansion pattern of alternative oxidase (AOX) genes." (2014). Plant Physiol. Biochem. 47, 753-759. doi: 10.1016/j.plaphy.2014.11.013.

Costa, JH., Mohanapriya, G., Bharadwaj R., Noceda, C., Thiers, K.L.L., Shahid, A., et al. (2021). ROS/RNS balancing, aerobic fermentation regulation and cell cycle control a complex early trait ('CoV-MAC-TED') for combating SARS-CoV-2-induced cell reprogramming. bioRxiv 2021.06.08.447491. doi: https://doi.org/10.1101/2021.06.08.447491

Doner, L.W., Becard, G. (1991). Solubilization of gellan gels by chelation of cations. Biotechnol Tech (1991) 5(1):25-28.

Dumont, S., Rivoal, J. (2019). Consequences of Oxidative Stress on Plant Glycolytic and Respiratory Metabolism. Front Plant Sci. 10:166. doi: 10.3389/fpls.2019.00166.

Durán, P., Tortella, G., Viscardi, S., Barra, P.J., Carrión, V.J., Mora, M.L., Pozo, M.J. (2018). Microbial Community Composition in Take-All Suppressive Soils. Front Microbiol 9:2198. doi: 10.3389/fmicb.2018.02198.

Eckert, C., Xu, W., Xiong, W., Lynch, S., Ungerer, J., Tao, L., et al. (2014). Ethylene-forming enzyme and bioethylene production. Biotechnol Biofuels. 7(1):33. doi: 10.1186/17546834-7-33. 
bioRxiv preprint doi: https://doi.org/10.1101/2021.06.08.447570; this version posted June 10, 2021. The copyright holder for this preprint (which was not certified by peer review) is the author/funder. All rights reserved. No reuse allowed without permission.

Fan, Y., Yu, X., Guo, H., Wei, J., Guo, H., Zhang, L., et al. (2020). Dynamic Transcriptome Analysis Reveals Uncharacterized Complex Regulatory Pathway Underlying Dose IBA Induced Embryogenic Redifferentiation in Cotton. Int J Mol Sci. 21(2):426. doi:10.3390/ijms21020426.

Grieb, B., Groß, U., Pleschka, E., Arnholdt-Schmitt, B., Neumann, K.H. (1994). Embryogenesis of photoautotrophic cell cultures of Daucus carota L. Plant Cell Tiss Organ Cult 38, 115-122.

Gupta, K.J., Kolbert, Z., Durner, J., Lindermayr, C., Corpas, F.J., Brouquisse, R., et al. (2020a). Regulating the regulator: nitric oxide control of post-translational modifications. New Phytol. 227(5), 1319-1325.

Gupta, K.J., Hancock. J.T., Petrivalsky. M., Kolbert. Z., Lindermayr. C., Durner. J., et al. (2020b). Recommendations on terminology and experimental best practice associated with plant nitric oxide research. New Phytol. 225(5), 1828-1834. doi: 10.1111/nph.16157.

Hakkaart, G.A., Dassa, E.P., Jacobs, H.T., Rustin P. (2006). Allotopic expression of a mitochondrial alternative oxidase confers cyanide resistance to human cell respiration. EMBO Rep. 7(3), 341-5. doi: 10.1038/sj.embor.7400601.

Hirschauer, N., Becker, C. Paradigmenwechsel Warum statistische Signifikanztests abgeschafft werden sollten. Signifikanztests Forschung \& Lehre 6:20.

Hoefnagel, M., Rich, P.R., Zhang, Q., Wiskich, J.T. (1997). Substrate Kinetics of the Plant Mitochondrial Alternative Oxidase and the Effects of Pyruvate. Plant Physiol. 115(3), 1145-1153. doi: 10.1104/pp.115.3.1145.

Ito, K., Ogata, T., Seito, T., Umekawa, Y., Kakizaki, Y., Osada, H., et al. (2020). Degradation of mitochondrial alternative oxidase in the appendices of Arum maculatum. Biochem J. 477(17), 3417-3431. doi: 10.1042/BCJ20200515.

Jayawardhane, J., Cochrane, D.W., Vyas, P., Bykova, N.V., Vanlerberghe, G.C., Igamberdiev A.U. (2020). Roles for Plant Mitochondrial Alternative Oxidase Under Normoxia, Hypoxia, and Reoxygenation Conditions. Front Plant Sci. 11:566. doi: 10.3389/fpls.2020.00566.

Kagi, J.H., Vallee, B.L. (1960). The role of zinc in alcohol dehydrogenase. V. The effect of metal-binding agents on thestructure of the yeast alcohol dehydrogenase molecule. $J$ Biol Chem 235, 3188-92.

Kutschera, U., Pieruschka, R., Farmer, S., Berry, J.A. (2020). The Warburg-effects: basic metabolic processes with reference to cancer development and global photosynthesis. Plant Signal Behav. 15(7):1776477. doi: 10.1080/15592324.2020.1776477.

Lara-Núñez, A., García-Ayala, B.B., Garza-Aguilar, S.M., Flores-Sánchez, J., SánchezCamargo, V.A., Bravo-Alberto, C.E., et al. (2017). Glucose and sucrose differentially modify cell proliferation in maize during germination. Plant Physiol Biochem. 113, 20-31. doi: 10.1016/j.plaphy.2017.01.018. 
bioRxiv preprint doi: https://doi.org/10.1101/2021.06.08.447570; this version posted June 10, 2021. The copyright holder for this preprint (which was not certified by peer review) is the author/funder. All rights reserved. No reuse allowed without permission.

Lin, X.Y., Ye, Y.Q., Fan, S.K., Jin, C.W., Zheng, S.J. (2016). Increased Sucrose Accumulation Regulates Iron-Deficiency Responses by Promoting Auxin Signaling in Arabidopsis Plants. Plant Physiol. 170(2), 907-20. doi: 10.1104/pp.15.01598.

Lucic-Mercy, E., Mercy, L., Lartigue, J., Thongo, A., Mercy, L., Hutter, I., et al. (2017). Oligosaccharides as Signals: A New Opportunity for Promoting Mycorrhizal Development and Effectiveness in Revegetation Programs? Dr. Dissertation, ICOM, Prague.

Machingura, M., Salomon, E., Jez, J.M., Ebbs, S.D. (2016). The $\beta$-cyanoalanine synthase pathway: beyond cyanide detoxification. Plant Cell Environ. 39(10), 2329-41. doi: 10.1111/pce.12755.

Meitzel, T., Radchuk, R., McAdam, E.L., Thormählen, I., Feil, R., Munz, E., et al. (2021). Trehalose 6-phosphate promotes seed filling by activating auxin biosynthesis. New Phytol. 229(3), 1553-1565. doi: 10.1111/nph.16956.

Melkonian, E.A., Schury, M.P. (2020). Biochemistry, Anaerobic Glycolysis. In: StatPearls [Internet]. Treasure Island (FL): StatPearls Publishing. 2021 Jan-. Available from: https://www.ncbi.nlm.nih.gov/books/NBK546695/.

Mellema, S., Eichenberger, W., Rawyler, A., Suter, M., Tadege, M., Kuhlemeier, C. (2002). The ethanolic fermentation pathway supports respiration and lipid biosynthesis in tobacco pollen. Plant J. (2002) 30(3), 329-36. doi: 10.1046/j.1365313x.2002.01293.x.

Mercy, L., Lucic-Mercy, E., Nogales, A., Poghosyan, A., Schneider, C., Arnholdt-Schmitt, B. (2017). A Functional Approach towards Understanding the Role of the Mitochondrial Respiratory Chain in an Endomycorrhizal Symbiosis. Front Plant Sci 8:417. doi:10.3389/fpls.2017.00417.

Mercy. L., Svensson, J.T., Lucic, E., Cardoso, H.G., Nogales, A., Döring M., et al. (2015). "AOX gene diversity in arbuscular mycorrhizal fungi (AMF) products - a special challenge" in Alternative Respiratory Pathways in Higher Plants. eds. KJ, Gupta, LAJ, Mur, B, Neelwarne. (Oxford: John Wiley \& Sons, Inc.), 305-310

Millar AH, Hoefnagel M, Day DA, Wiskich JT. Specificity of the Organic Acid Activation of Alternative Oxidase in Plant Mitochondria. Plant Physiol (1996) 111(2):613-618. doi: 10.1104/pp.111.2.613.

Mohanapriya, G., Bharadwaj, R., Noceda, C., Costa, J.H.. Kumar, S.R., Sathishkumar, R., et al. (2019). Alternative Oxidase (AOX) Senses Stress Levels to Coordinate AuxinInduced Reprogramming From Seed Germination to Somatic Embryogenesis-A Role Relevant for Seed Vigor Prediction and Plant Robustness. Front. Plant Sci. 10:1134. doi: 10.3389/fpls.2019.01134.

Moon, H., Lee, H., Paek, K., Park, S. (2015). Osmotic stress and strong 2,4-D shock stimulate somatic-to-embryogenic transition in Kalopanax septemlobus (Thunb.) Koidz. Acta Physiol Plant. 37:1710. doi:10.1007/s11738-014-1710-x.

Mortazavi, A., Williams, B.A., Mccue, K., Schaeffer, L., Wold, B. (2008). Mapping and quantifying mammalian transcriptomes by RNA-Seq. Nat Methods 5, 621-628. 
bioRxiv preprint doi: https://doi.org/10.1101/2021.06.08.447570; this version posted June 10, 2021. The copyright holder for this preprint (which was not certified by peer review) is the author/funder. All rights reserved. No reuse allowed without permission.

Narsai, R., Secco, D., Schultz, M.D., Ecker, J.R., Lister, R., Whelan, J. (2017). Dynamic and rapid changes in the transcriptome and epigenome during germination and in developing rice (Oryza sativa) coleoptiles under anoxia and re-oxygenation. Plant J. 89(4), f805-824. doi: 10.1111/tpj.13418.

Nascimento, W.M., Huber, D.J., Cantliffe, D.J. (2013). Carrot seed germination and respiration at high temperature in response to seed maturity and priming. Seed Science and Technology. 41(1), 164-169.

Nguyen, H.M., Sako, K., Matsui, A., Suzuki, Y., Mostofa, M.G., Ha, C.V., et al. (2017). Ethanol Enhances High-Salinity Stress Tolerance by Detoxifying Reactive Oxygen Species in Arabidopsis thaliana and Rice. Front Plant Sci. 8:1001. doi: 10.3389/fpls.2017.01001.

Nogales, A., Muñoz-Sanhueza, L., Hansen, L. D., Arnholdt-Schmitt, B. (2015). Phenotyping carrot (Daucus carota L.) for yield-determining temperature response by calorespirometry. Planta 241 (2), 525-538. doi: 10.1007/s00425-014-2195-y.

Nogales, A., Nobre, T., Cardoso, H.G., Muñoz-Sanhueza, L., Valadas, V., Campos, M.D, et al. (2016). Allelic variation on DcAOX1 gene in carrot (Daucus carota L.): an interesting simple sequence repeat in a highly variable intron. Plant Gene. 5, 49-55. doi:10.1016/j.plgene.2015.11.001.

Paszkiewicz, G., Gualberto, J.M., Benamar, A., Macherel, D., Logan DC. (2017). Arabidopsis Seed Mitochondria Are Bioenergetically Active Immediately upon Imbibition and Specialize via Biogenesis in Preparation for Autotrophic Growth. Plant Cell. 29(1), 109-128. doi: 10.1105/tpc.16.00700.

Pengpeng, J., Chenyu, D., Penghu, C., Dong, S., Ruizhuo, O., Yuqing, M. (2020). The role of reactive oxygen species in tumor treatment. $R S C A d v .10(13), 7740-7750$.

Porfirio, S., Calado, M. L., Noceda, C., Cabrita, M. J., da Silva, M. G., Azadi, P., et al. (2016). Tracking biochemical changes during adventitious root formation in olive (Olea europaea L.). Sci. Hort. 204, 41-53. doi: 10.1016/j.scienta.2016.03.029.

Powell A.A. (2017). A review of the principles and use of the Q2 Seed Analyser. International Seed Testing Association (ISTA). Print date: 15.06.17. pp:1-15.

Qi, W., Ma, L., Wang, F., Wang, P., Wu, J., Jin, J., et al. (2020). Reactive oxygen species as important regulators of cell division. bioRxiv. Preprint available.

Regulation (EU) 2018/848 of the European Parliament and of the Council of 30 May 2018 on organic production and labelling of organic products and repealing Council Regulation (EC) No 834/2007. OJ L 150, 14.6.2018, p. 1-92.

Sakr, S., Wang, M., Dédaldéchamp, F., Perez-Garcia, M.D., Ogé, L., Hamama, L., et al. (2018). The Sugar-Signaling Hub: Overview of Regulators and Interaction with the Hormonal and Metabolic Network. Int J Mol Sci. 19(9):2506. doi: 10.3390/ijms19092506.

Saleh, T., Kalodimos, C.G. (2017). Enzymes at work are enzymes in motion. Science. 355(6322), 247-248. doi: 10.1126/science.aal4632. 
bioRxiv preprint doi: https://doi.org/10.1101/2021.06.08.447570; this version posted June 10, 2021. The copyright holder for this preprint (which was not certified by peer review) is the author/funder. All rights reserved. No reuse allowed without permission.

Sangüesa, G., Roglans, N., Baena, M., Velázquez, A.M., Laguna, J.C., Alegret, M. (2019). mTOR is a Key Protein Involved in the Metabolic Effects of Simple Sugars. Int J Mol Sci. 20(5):1117. doi: 10.3390/ijms20051117.

Santos Macedo, E., Cardoso, H.G., Hernández, A., Peixe, A.A., Polidoros, A., Ferreira, A., et al. (2009). Physiologic responses and gene diversity indicate olive alternative oxidase as a potential source for markers involved in efficient adventitious root induction. Physiol Plant 137(4), 532-52. doi: 10.1111/j.1399-3054.2009.01302.x.

Saraiva, K.D., Oliveira, A.E., Santos, C.P., Lima, K.T., Sousa, J.M., Melo, D.F., et al. (2016). Phylogenetic analysis and differential expression of EF1 $\alpha$ genes in soybean during development, stress and phytohormone treatments. Mol. Genet. Genomics 291, 15051522. doi: 10.1007/s00438-016-1198-8.

Schmidt, R.R., Weits, D.A., Feulner, C.F.J., van Dongen, J.T. (2018). Oxygen Sensing and Integrative Stress Signaling in Plants. Plant Physiol. 176(2), 1131-1142. doi:10.1104/pp.17.01394.

Selinski, J., Hartmann, A., Deckers-Hebestreit, G., Day, D.A., Whelan, J., Scheibe, R. (2018). Alternative Oxidase Isoforms Are Differentially Activated by Tricarboxylic Acid Cycle Intermediates. Plant Physiol. 176(2):1423-1432. doi: 10.1104/pp.17.01331.

Siegień, I., Bogatek, R. (2006). Cyanide action in plants — from toxic to regulatory. Acta Physiol Plant. 28, 483-497.

Simon, P.W., Navazio, J.P., Colley, M., McCluskey, C., Zystro, J., Hoagland, L et al. (2017). The CIOA (Carrot Improvement for Organic Agriculture) project: location, cropping system and genetic background influence carrot performance including top height and flavour. Acta Horticulturae 1153:1-8. doi: 10.17660/ActaHortic.2017.1153.1.

Sircar, D., Cardoso, H.G., Mukherjee, C., Mitra, A., Arnholdt-Schmitt, B. (2012). Alternative oxidase (AOX) and phenolic metabolism in methyl jasmonate-treated hairy root cultures of Daucus carota L. J Plant Physiol. 169(7), 657-63. doi: 10.1016/j.jplph.2011.11.019.

Srivastava, S., Conlan, X.A., Cahill, D.M., Adholeya, A. (2016). Rhizophagus irregularis as an elicitor of rosmarinic acid and antioxidant production by transformed roots of Ocimum basilicum in an in vitro co-culture system. Mycorrhiza. 26, 919-30.

Vanlerberghe, G.C., Vanlerberghe, A.E., McIntosh, L. (1994). Molecular Genetic Alteration of Plant Respiration (Silencing and Overexpression of Alternative Oxidase in Transgenic Tobacco). Plant Physiol. 106(4), f1503-1510. doi: 10.1104/pp.106.4.1503.

Vicente, C., Costa, J.H., Arnholdt-Schmitt, B. (2015). Bacterial AOX: a provocative lack of interest! In Alternative respiratory pathways in higher plants. eds. KJ Gupta, LA Mur, B Neelwarne (Wiley Publishing group), 319-322

Vicente, S.L.C., Arnholdt-Schmitt B. (2008). Characterization of Mediterranean AMs: Initiation of a novel functional marker approach. Proceedings COST 870 Meeting, Greece, September 17-19, p.45-48. 
bioRxiv preprint doi: https://doi.org/10.1101/2021.06.08.447570; this version posted June 10, 2021. The copyright holder for this preprint (which was not certified by peer review) is the author/funder. All rights reserved. No reuse allowed without permission.

Voss-Fels, K.P., Cooper, M., Hayes, B.J. (2019). Accelerating crop genetic gains with genomic selection. Theor Appl Genet. 132(3), 669-686. doi: 10.1007/s00122-0183270-8.

Wang, W.R., Liang, J.H., Wang, G.F., Sun, M.X., Peng. F.T., Xiao. Y.S. (2020). Overexpression of PpSnRK1 $\alpha$ in tomato enhanced salt tolerance by regulating ABA signaling pathway and reactive oxygen metabolism. BMC Plant Biol. 20(1):128. doi: 10.1186/s12870-020-02342-2.

Wassermann, B., Cernava, T., Müller, H., Berg, C., Berg, G. (2019). Seeds of native alpine plants host unique microbial communities embedded in cross-kingdom networks. Microbiome. 7(1):108. doi: 10.1186/s40168-019-0723-5.

Wojtyla, Ł., Lechowska, K., Kubala, S., Garnczarska, M. (2016). Different Modes of Hydrogen Peroxide Action During Seed Germination. Front Plant Sci. 7:66. doi: 10.3389/fpls.2016.00066.

Wurzinger, B., Nukarinen, E., Nägele, T., Weckwerth, W., Teige, M. (2018). The SnRK1 Kinase as Central Mediator of Energy Signaling between Different Organelles. Plant Physiol 176(2), 1085-1094. doi: 10.1104/pp.17.01404.

Zabalza, A., van Dongen, J.T., Froehlich, A., Oliver, S.N., Faix, B., Gupta, K.J., et al. (2009). Regulation of respiration and fermentation to control the plant internal oxygen concentration. Plant Physiol. 149(2), 1087-98. doi: 10.1104/pp.108.129288.

Zavattieri, M.A., Frederico, A.M., Lima, M., Sabino, R., Arnholdt-Schmitt, B. (2010). Induction of somatic embryogenesis as an example of stress-related plant reactions. Journal of Biotechnology (2010) 13:1. doi: 10.2225/vol13-issue1-fulltext-4.

Zhao, J., Li, W., Sun, S., Peng, L., Huang, Z., He, Y., et al. (2021). The Rice Small Auxin-Up RNA Gene OsSAUR33 Regulates Seed Vigor via Sugar Pathway during Early Seed Germination. Int J Mol Sci. 22(4):1562. doi: 10.3390/ijms22041562.

Zhu, T., Zou, L., Li, Y., Yao, X., Xu, F., Deng, X., et al. (2018). Mitochondrial alternative oxidase-dependent autophagy involved in ethylene-mediated drought tolerance in Solanum lycopersicum. Plant Biotechnol J. 16(12):2063-2076. doi: 10.1111/pbi.12939. 


\section{Figure Legends:}

Figure 1: Step-by-step rationale of our perspective

\section{A.1 Exogenous sucrose postponed germination of endophyte-free (EFS) and} superficially sterilized (SSS) carrot seeds: sucrose inhibited early germination (at 48 hours after imbibition (HAI)) dependent on increasing sugar concentrations. This trend was the same for seeds treated to become endophyte-free and seeds that were superficially sterilized. At $120 \mathrm{HAI}$, the effect of 0.5 to $3 \%$ sucrose could not be noticed anymore, while $7 \%$ sucrose inhibited germination for a prolonged time. This observation indicates a critical role of sucrose during induction of adaptive performance. For confirmation of this role of sucrose, in supplementary Figure S1, the effect of sucrose is shown for auxin-dependent early induction of somatic embryogenesis (SE) as the most studied example of de novo programming. It demonstrates that (a) sugar is essential for cell reprogramming, since SE induction was not observed at around 45 DAI in controls, but only at $2 \%$ and $3 \%$ sucrose supply and (b) that SE can be optimized with the help of increasing amounts of exogenous sucrose, since SE induction efficiency was highest at 3\% sucrose (Supplementary table S1). Cell reprogramming competes with cell division. This is a common insight, which got here validated again through the observed delay in embryonic versus non-embryonic callus emergence by increasing sucrose concentrations at lower levels. As a general tendency, at increasing sucrose levels, less seeds showed callus growth, which later demonstrated to be embryogenic, in comparison to the higher number of seeds with (non-embryogenic) callus growth at low sucrose levels (Figure S1).

A.2 Short early pulses of sucrose enhanced early germination in carrot seeds: $3 \%$ sucrose applied for $2 \mathrm{~h}$ or $10 \mathrm{~h}$ from imbibition enhanced early germination to about the same degree compared to the control and to a longer pulse of $30 \mathrm{~h}$. A lower sucrose concentration of $0.5 \%$ had the highest effect only by a longer pulse of $10 \mathrm{~h}$ and, at $7 \%$ sucrose a higher effect against the control was only indicated when given as a short pulse of $2 \mathrm{~h}$. This observation was confirmed with a second carrot cultivar in a rapid on-farm check by using a ca. 5\% solution of commercial sugar (significant) (Figure S2).

\section{A.3 Exogenous sucrose enhanced the level of alcohol-dehydrogenase (ADH) at 12HAI} during carrot germination: At $12 \mathrm{HAI}$, treatment with $0.5 \%$ and $3 \%$ sucrose resulted in 
377

378

379

380

381

382

383

384

385

386

387

388

389

390

391

392

393

394

395

396

397

398

399

400

401

402

403

404

405

406

407

408

409

410

observed. At $24 \mathrm{HAI}$, the control indicated decline of ADH values. In the presence of $0.5 \%$ and 3\% sucrose, this decline was not avoided or might even have been strengthened. However, at $30 \mathrm{HAI}$, a second phase started, where sucrose enhanced the level of ADH in a concentration-dependent manner including a positive effect of $7 \%$ sucrose.

B.1 SHAM affects early germination and this links to expression of AtAOX1a: In wildtype Arabidopsis thaliana seeds, monitoring germination at 72 HAI showed that SHAM treatment led to reduced germination rates. This inhibition was dependent on its concentration of 0.5 or $1.5 \mathrm{mM}$. However, when AOX had been silenced (AS), SHAM did not affect germination. To the contrary, when AOX was constitutively overexpressed (OE), SHAM indicated stronger inhibition of germination than in the wildtype. Nevertheless, the three genotypes germinated with similar efficiency in relation to their respective controls. This latter observation points to the fact that AOX is critically important for germination, if present. However, in case it is not present or activated (AS) alternative pathways can substitute the functional role of AOX during germination.

B.2 AtAOX1a and AtADH1+2 transcripts accumulated simultaneously: a study on ADH transcript accumulation in wildtype Arabidopsis thaliana confirmed a biphasic activation of $A D H$ during germination. A first increase was observed $12 \mathrm{~h}$ after stratification (significant), which includes imbibition of water. The second enhancement occurred from $12 \mathrm{~h} \mathrm{SL}$ shortly before root emergence was monitored at $24 \mathrm{~h}$ SL. In parallel to increased $A D H$ transcript accumulation, AOXIa transcripts accumulated during both phases, i.e. induction and early initiation of germination. After early induction, $A D H$ transcripts showed a high decline (significant) until the end of the dark stratification phase, while AOXIa transcript levels remained more stable. During the second phase at initiation of exponential root length growth in light observed at $48 \mathrm{~h}$ SL, AOXIa transcript accumulation keeps on enhancing, while the increase of ADH transcripts stopped at that time point. This was also indicated at the first phase. AOX2 transcript accumulation was differentially regulated in comparison to AOXIa and showed continuous down-regulation during the whole period, which appeared to be stronger in the SL phase.

\section{B.3 Seeds germinating at 3\% sucrose showed higher ADH levels at 12HAI and 30HAI:}

during early germination of carrot seeds, ADH levels follow a parable, when monitored between 12 and 30 HAI. This was observed in control seeds and seeds germinating at 3\% 
sucrose. Nevertheless, suppressed germination at 3\% sucrose was linked to higher levels of $\mathrm{ADH}$ at $12 \mathrm{HAI}$ and at $30 \mathrm{HAI}$. This means, the more efficient germination in control seeds was linked at these two time points to lower levels of ADH. Under both conditions, in the absence of exogenous sucrose and at 3\% sucrose, 24 HAI displayed a turning point with lowest ADH activity levels. However, ADH activity at $24 \mathrm{HAI}$ was higher in controls (significant) than under conditions of sucrose-supplementation.

\section{B.4 Robustness in chickpea linked to increased ADH levels in seeds at 10HAI in two} temperatures: early chickpea plant vigor is critical for plant productivity under terminal drought conditions (Sivasakthi et al., 2017). From the two principle chickpea types, Desi and Kabuli, vast field experience has shown that Desi is clearly superior in terms of multistress tolerance and yield performance (Purushothaman et al., 2014). We could in a former research discriminate both types at $10 \mathrm{HAI}$ by a lower oxycaloric equivalent $(\mathrm{Rq} / \mathrm{RCO} 2)$ value due to differential carbon use and, thus, predict posteriori the known better yield stability of Desi (Gunasekaran et al. 2019). Here we show that Desi increased the level of $\mathrm{ADH}$ at $10 \mathrm{HAI}$ during germination (significant at $23^{\circ} \mathrm{C}$ and $28^{\circ} \mathrm{C}$ ), while this was not seen in Kabuli. The reached level of $\mathrm{ADH}$ was higher at $23^{\circ} \mathrm{C}$ than at $28^{\circ} \mathrm{C}$.

\section{B.5 Pronounced SHAM-effects on ADH levels at 24HAI that show interaction with}

sucrose: during the germination of carrot seeds, the most pronounced effect of SHAMtreatment on $\mathrm{ADH}$ levels was observed at $24 \mathrm{HAI}$. At that time point, SHAM stimulated ADH level compared to levels observed at $12 \mathrm{HAI}$ and $30 \mathrm{HAI}$. This happened independent of the presence of sucrose (3\%). However, under both conditions, 5 mM SHAM showed a stronger stimulating effect on ADH levels (significant) at 24 HAI than 10 mM SHAM. But the level of SHAM-enhanced ADH was higher at both the tested concentrations of SHAM when sucrose was not present. To the contrary, at both time points $12 \mathrm{HAI}$ and $30 \mathrm{HAI}$, a higher $\mathrm{ADH}$ level in the $0 \%$ sucrose controls was associated to higher concentration of SHAM $10 \mathrm{mM}$ versus $5 \mathrm{mM}$ SHAM. At $3 \%$ sucrose, $\mathrm{ADH}$ activity was at any time point higher at 5mM SHAM than at 10mM SHAM. Together, these observations point to the importance of differential AOX activity-regulation for optimized germination during all three time points independently on the presence or absence of exogenous sucrose.

C.1 SHAM pulses $\leq 12 \mathrm{HAI}$ impact germination efficiency and interact with sucrose effects: in control seeds, short pulses of SHAM (10mM) until 12 HAI enhanced 
germination efficiency and were more effective than pulses until 6 HAI. However, prolonged SHAM treatment of 72 HAI suppressed early germination. In contrast, at 3\% exogenous sucrose, early germination efficiency was reduced against $0 \%$ sucrose controls (confirming Figure 1.A.1) and SHAM pulses until 6 HAI and 12 HAI led to complete suppression of early germination. However, from $48 \mathrm{HAI}$ onwards to $72 \mathrm{HAI}$, continuous SHAM treatment in the presence of $3 \%$ sucrose increased germination, while under $0 \%$ sugar continuous SHAM suppressed germination also at 72 HAI. Collectively, these results show that plastic AOX regulation was critical for the timing of germination in controls and under conditions of sucrose supplementation.

\section{C.2 10HAI and 30-40HAI are critical times for sucrose-SHAM interaction during}

carrot germination: $10 \mathrm{~h}$ of previous water imbibition reduced the strong negative effects of a combination of exogenous sucrose (3\%) and SHAM (5 mM) on germination efficiency that were observed at only $2 \mathrm{~h}$ of previous water imbibition (significant). Also during the phase of initiated root emergence at $30 \mathrm{HOI}$ (hours of imbibition) a transfer from water to media supplemented with sucrose and SHAM suppressed germination (significant). Water imbibition until $40 \mathrm{~h}$ before transfer to sucrose- and SHAM-containing media relieved and even supported germination when monitored at 30 HAI and at 48 HAI (significant). However, this increase in germination efficiency seemed to be restricted from 72 HAI onwards (significant).

\section{Sucrose and SHAM can improve the effect of AMF on early germination: in Figure}

1.D.1, it can be seen that carrot seeds, which were treated with native endophytes (isolated from cv. Kuroda) tended to improve early germination at 48HAI in both the cultivars (not seen for EN3 in cv. Early Nantes). Exogenous sucrose had differential effects depending on endophyte and cultivar (Figure 1.D.2), but in no case could sucrose enhance early germination rates compared to the respective endophyte-treated control (see also Supplementary Table S2). However, SHAM treatment (Figure 1.D.2) reduced early germination against endophyte-treated controls in all cases (see also Table S2). In a separate trial, two AMF strains (M1 and M2) from the species Rhizophagus were tested and acted negatively on germination in cv. Kuroda, but positively in slowly germinating seeds of cv. Early Nantes (Figure 1.D.1). Nevertheless, the effect of M1 on early germination could be improved in cv. Kuroda by $0.5 \%$ sucrose and $3 \%$ sucrose (Figure 
concentration of $5 \mathrm{mM}$ SHAM (Figure 1.D.2) improved the effect of both mycorrhiza species on early germination. In later germinating seeds of cv. Early Nantes, $0.5 \%$ sucrose improved the already positive effect on germination (Figure 1.D.1) of Rhizophagus strain M1 (Figure 1.D.2). In this cultivar, SHAM decreased the germination rate to the level of the untreated control (Table S2).

\section{E.1. On-farm organic vs conventional seed discrimination and organic breeding by} help of quick germination tests, commercial sugar and SHAM treatment: seeds from 6 of 7 winter wheat cultivars originating from organic agricultural management could be discriminated at $15 \mathrm{HAI}$ through better germination against conventionally produced seeds when germinated in 5\% sugar solution. In water, seeds of only 4 cultivars showed better germination for organic seeds. When conventionally produced material was compared, seeds of cultivar 1 showed poor germination. This was much more pronounced, when tested in $5 \%$ sugar solution instead of water. Seeds of cultivar 2 demonstrated highest germination rates among all tested cultivars (see Figure S4). This was observed for seeds originating from both agricultural conditions, although higher germination in 5\% sugar solution indicated the presence of microbiota (Figure 1.E.1). In contrast to all other cultivars, seeds of cultivar 2 did not differ in germination rates for organic vs conventional production under SHAM treatment when compared to the water control (see also Figure S4). This signals already low levels of $A O X$ at 15 HAI for this cultivar no matter from which agricultural management system seeds originated. Overall, these observations indicate interplay between plant genotype, sugar and AOX activity that impacts differential germination capacities between organic and conventional seeds.

\section{E.2. Identification of disease tolerant pea seeds by germination tests under SHAM-} discrimination ( $\mathbf{T}$ - tolerant reference; $\mathbf{S}$ - susceptible reference): Pea lines with differential degrees of root rot disease susceptibility could be ranked by employing SHAMinhibition. The most tolerant line (T) showed the lowest degree of SHAM-related inhibition of germination monitored at $27 \mathrm{HAI}$. This indicates the reasonability of germination tests under SHAM discrimination for selection of seed vigor and plant robustness.

\section{E.3. On-farm simple seed germination improvement of stored conventional and} organic wheat seeds by a $2 \mathrm{~h}$ initial pulse with commercial sugar (cultivar 1 in 1.E.1): this figure demonstrates the general potential of improving early germination through a 
511 short pulse of sugar and its validity across species (here winter wheat, see for carrot Figures

512 1.A.2 and S2), agricultural management practices and also related to the aging of seeds.

513

514 Figure 2: A simplified scheme on hypothesis and conceptualization for working out

515 metabolic principles on dynamic cell reprogram-functioning (details explained in text)

516

517 Supplementary Tables:

518 S1: Table S1: Effect of exogenous sucrose concentration on carrot SE callus induction

S2: Table S2: Microbiota effect on carrot seed germination at different sucrose and SHAM concentrations

522

\section{Supplementary figures:}

524 S1: Exogenous sucrose delayed callus emergence and was necessary for SE

S2: $2 \mathrm{~h}$ pulse with commercial sugar improved carrot germination efficiency monitored at $40 \mathrm{HAI}$ and $50 \mathrm{HAI}$

S3: Effect of SHAM treatment on accumulation of soluble and wall bound phenolics (A) and flavonoids and lignin (B) in elicitor-treated hairy roots of Daucus carota. Values obtained in only elicitor-treated root was considered as $100 \%$ and results were expressed in terms of percentage of maximum. The terms $\mathrm{E}$ and $\mathrm{NE}$ in the $\mathrm{x}$-axis legend denote -with

533 and -without elicitor, respectively. * Soluble phenolics. Values are mean of three 534 independent experiments \pm SD.

S4: Rapid germination check of organic and conventional seeds from seven cultivars in water (control) or under SHAM (5 mM) treatment 
bioRxiv preprint doi: https://doi.org/10.1101/2021.06.08.447570; this version posted June 10, 2021. The copyright holder for this preprint (which was not certified by peer review) is the author/funder. All rights reserved. No reuse allowed without permission.

Figure 01: Step-by-step rationale of our perspective

Figure 1: Step-by-step rationale of our perspective - Fundamental Insights
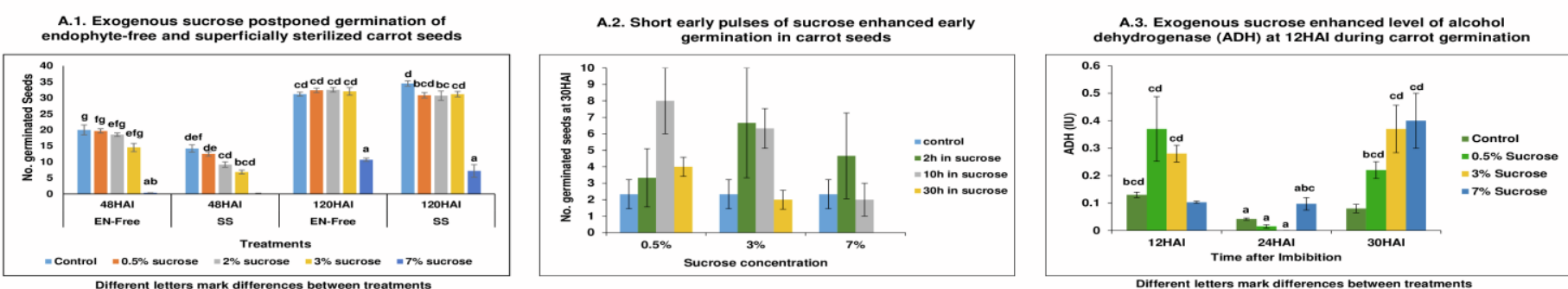

B.1. SHAM affects early germination, this is linked to expression of AtAOX1a

\begin{tabular}{|c|c|c|c|}
$\begin{array}{c}\text { Germination at } \\
\mathbf{7 2 H A l}\end{array}$ & Wild type & $\begin{array}{c}\text { Anti-Sense } \\
\text { (suppressed } \\
\text { expression) }\end{array}$ & Overexpression \\
\hline Control & ALL & ALL & ALL \\
\hline $\mathbf{0 . 5}$ mM SHAM & FEW & ALL & NONE \\
\hline $\mathbf{1 . 5} \mathrm{mM} \mathrm{SHAM}$ & ca. $50 \%$ & ALL & FEW \\
\hline $\mathbf{2 . 5}$ mM SHAM & NONE & NONE & NONE \\
\hline
\end{tabular}

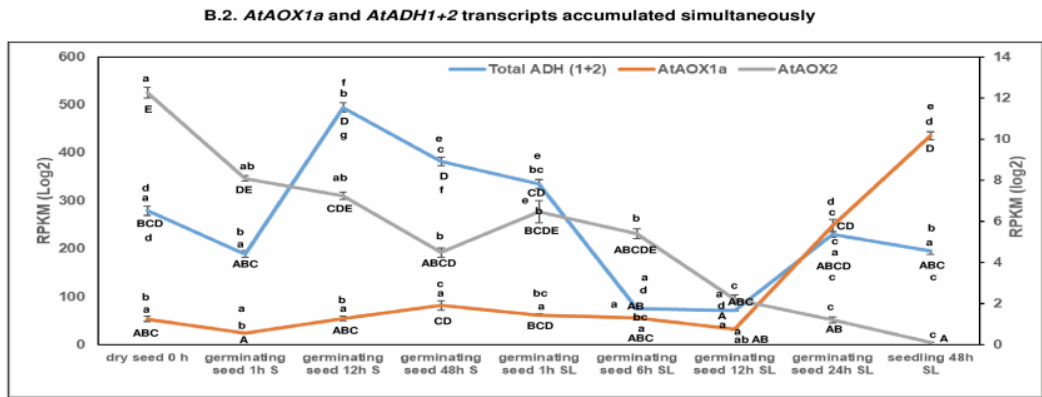

B.3. Seeds germinating at $3 \%$ sucrose showed higher

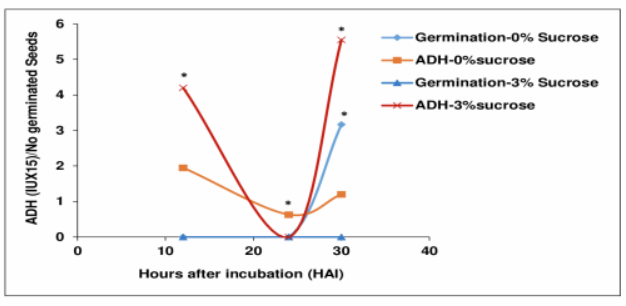

B.4. Robustness in chickpea is linked to increased ADH

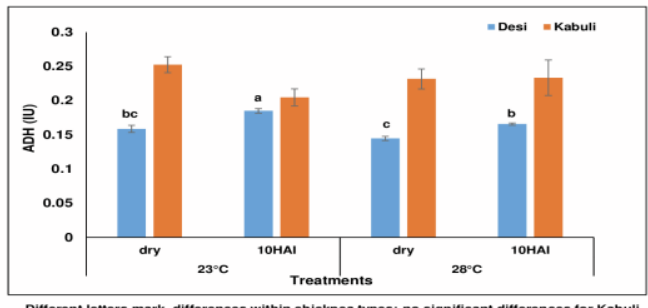

B.5. Pronounced SHAM-effects on ADH levels at 24HAl that

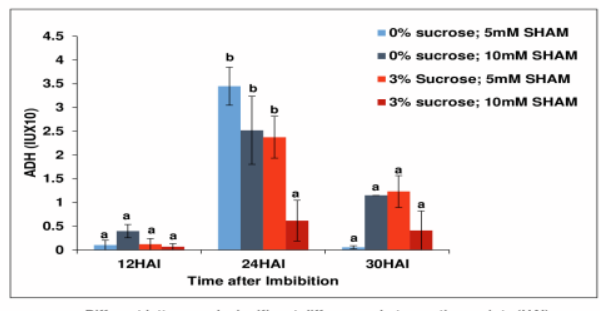

C.1. SHAM pulses $\leq 12 \mathrm{HAl}$ impact germination efficiency and interact with sucrose effects

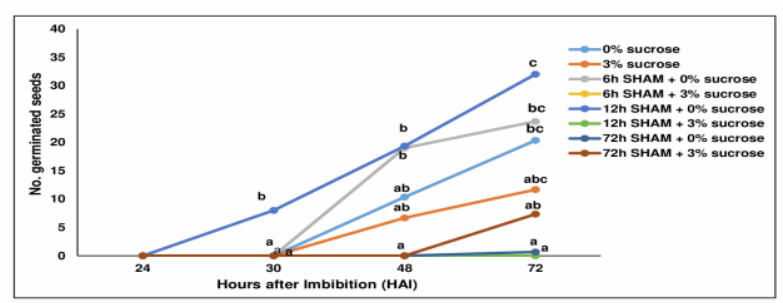

Different letters mark differences at one time points (HAI)

D.1. Carrot bacterial endophyte and AMF effects on early carrot germination

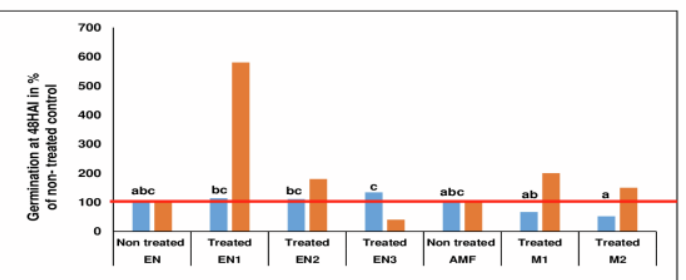

Treatments

-Kuroda $\quad=E$, Nantes
C.2. 10HAl and 30-40HAl are critical times for sucrose-SHAM interaction during carrot germination

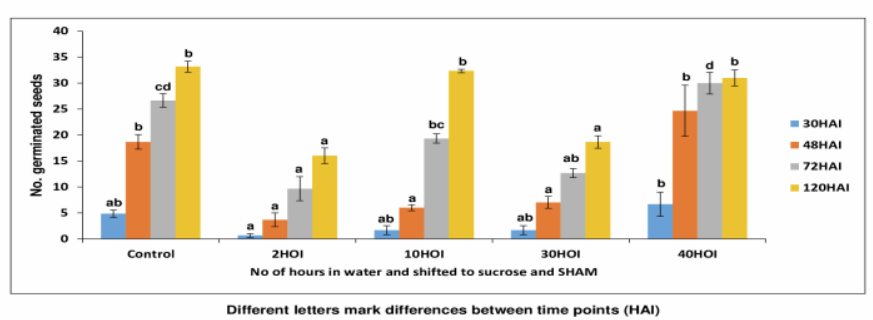

D.2. Sucrose and SHAM can improve the effect of AMF on early carrot germination

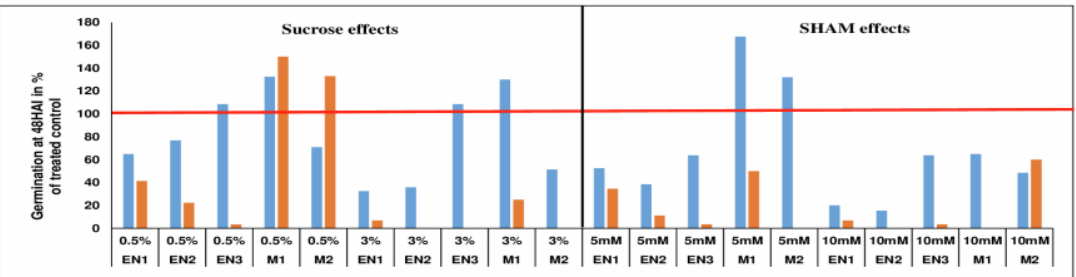

Perspectives for simple and rapid on-farm and service seed improvement - open for validation E.1 On-farm organic vs conventional seed discrimination and organic breeding by help of quick germination tests, commercial sugar and SHAM treatment

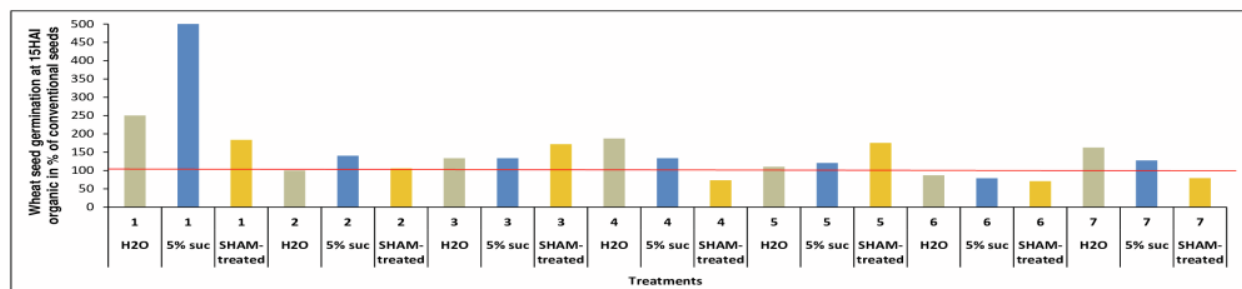

E.2. Identification of disease tolerant pea seeds by germination tests under SHAM-
discrimination (References: $\mathrm{T}$ - tolerant reference; $\mathrm{S}$ - susceptible reference)

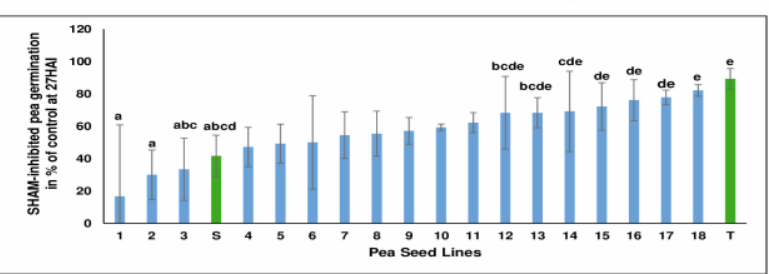

E.3. On-farm simple seed germination improvement of stored conventional and
organic wheat seeds by a $2 \mathrm{~h}$ initial pulse with commercial sugar (cultivar 1 in E.1)

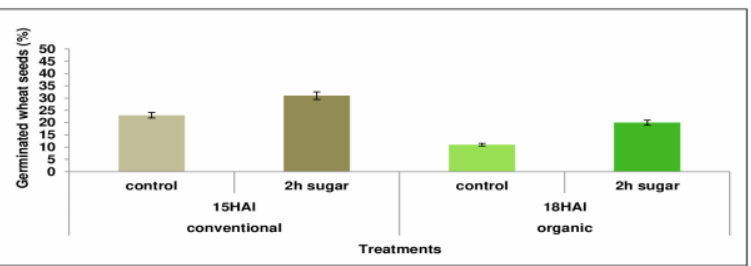


Figure 02: A simplified scheme on hypothesis and conceptualization for working out metabolic principles on dynamic cell reprogram-functioning

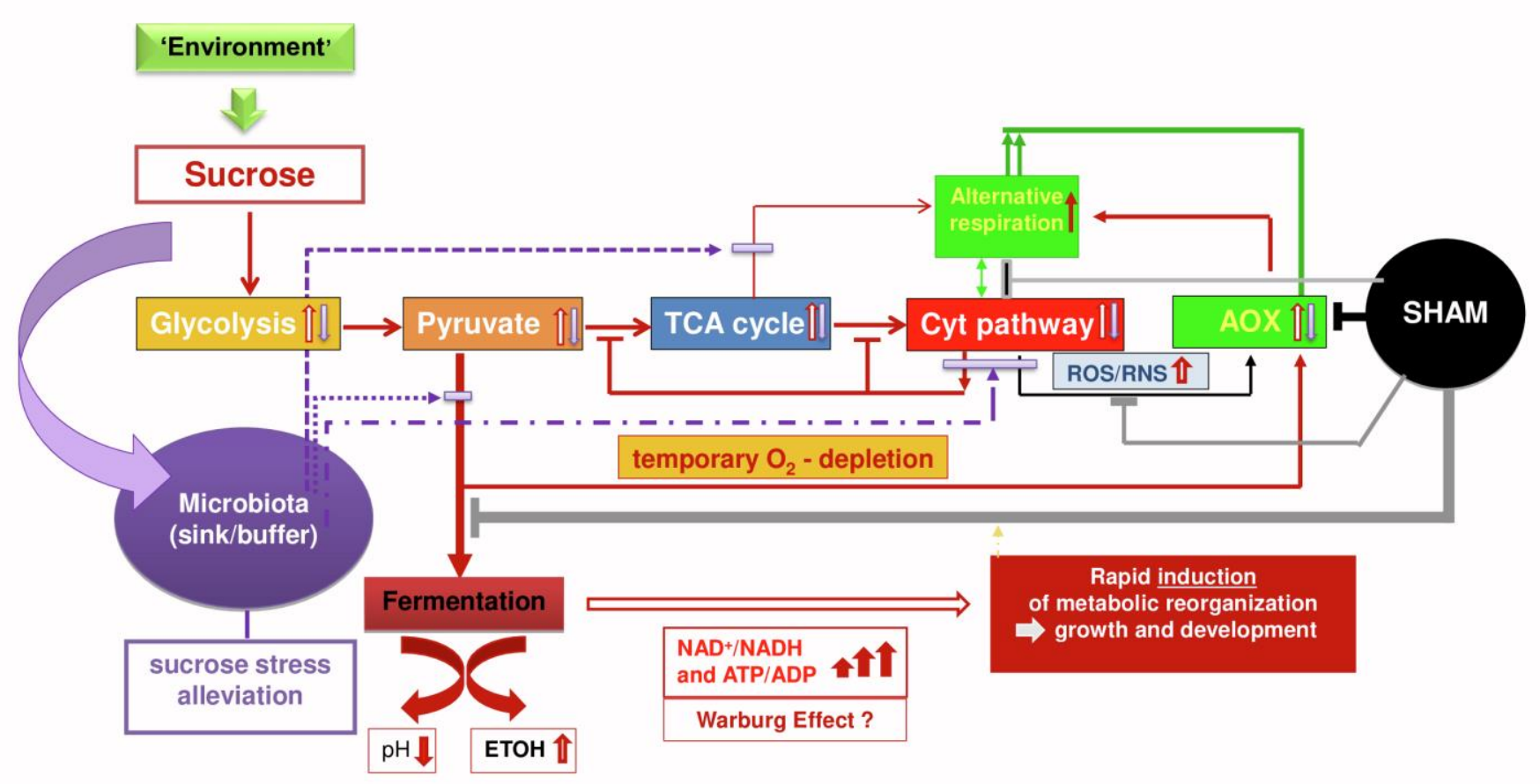

